\title{
Investments, Technical Change and Efficiency: Empirical Evidence from Czech Food Processing
}

\author{
Tamara Rudinskaya ${ }^{1}$, Elena Kuzmenko ${ }^{2}$ \\ ${ }^{1}$ Institute of Agricultural Economics and Information, Prague, Czech Republic \\ ${ }^{2}$ Faculty of Economics and Management, Czech University of Life Sciences in Prague, Czech Republic
}

\begin{abstract}
This empirical study aims to shed light on the dynamic linkages among investments, technical efficiency and productivity of food processing at a sectoral level. We use data obtained from meat and milk processing firms operating in the Czech Republic. The data set covers a period from 2011 to 2015. Being based on a production function frontier framework and the Divisia index our study is focuses on the estimation of technical efficiency and productivity of Czech Food processing firms in connection with the received investments. The results of the conducted analysis have shown that investments, directed to a production process of meat and milk processing firms operating in the Czech Republic, do have a positive effect on their technical efficiency. Moreover, it provides an opportunity to increase the capacity of raw milk processing. Higher TFP in food processing industry may result in higher TFP in agriculture.
\end{abstract}

\section{Keywords}

Technical efficiency, Technical change, Investments, Czech food processing, Divisia index.

Rudinskaya, T. and Kuzmenko, E. (2019) "Investments, Technical Change and Efficiency: Empirical Evidence from Czech Food Processing", AGRIS on-line Papers in Economics and Informatics, Vol. 11, No. 4, pp. 93-103. ISSN 1804-1930. DOI 10.7160/aol.2019.110409.

\section{Introduction}

Recent years a growing interest have been observed in empirical studies aimed at analysing productivity and efficiency of firms that can be increased thanks to investment support. The most frequently used methodology for impact assessment is based on the Data Envelopment Analysis (DEA) and Stochastic Frontier Analysis (SFA). Difficulties with the estimation of effects stemming from investment support on efficiency and productivity of firms in EU Member States were discussed by Bergschmidt et al. (2006), Coelli et al. (2006), Bergschmidt (2009), Forstner et al. (2009), Bernini a Pellegrini (2011) and others. Beck and Dogot (2006) proposed the impact indicators of investment support for assessment possible effects. They found that in the short run there were no connections between investments and firms' income growth. However, in the long run investments did have a positive effect on both farm's competitiveness and sustainability. Špicka and Machek (2015) analysed changes in efficiency resulted from investment activity and allocation of subsidies to firms specializing on milk processing in 100 EU regions over the period 2007 to 2011.
They found that investment subsidies per livestock unit are slightly higher in regions with a negative change in the production efficiency. Thus, such investment subsidies continuously helped them to mitigate the decline in their technical efficiency. The impact of Rural Development Program (RDP) subsidies on food industry was analysed by Mezera and Špicka (2013). According to their results, subsidies positively affect not just financial stability, but also increase labour productivity. According to Ferto et al. (2012) subsidized producers can invest in farm development and achieve higher technical progress since they are less credit constrained. Ratinger et al. (2014) analysed factors of Czech farm participation in investment support scheme. They found significant positive effects of investment support on gross value added and improvement of labour productivity.

Most studies analysed investment impact through the analysis of the subsidies effect, which was substituted by investment support policies granted under the EU RDP (Ciaian et al., 2015; Hurńáková et al., 2016). However, the subsidies on investment do not cover all sources of investment. Besides these subsidies themselves, investments 
may be funded by a firm's own sources. In this paper we assume to analyse the total investment without separation of financing sources.

\begin{tabular}{|c|c|c|}
\hline CZ-NACE group & $\begin{array}{c}\text { Share } \\
\text { in turnover, } \%\end{array}$ & $\begin{array}{c}\text { Share in number } \\
\text { of employees, \% }\end{array}$ \\
\hline 10.1 & 23.2 & 24.4 \\
\hline 10.2 & 0.9 & 0.9 \\
\hline 10.3 & 3.0 & 3.5 \\
\hline 10.4 & 4.8 & 1.0 \\
\hline 10.5 & 14.4 & 9.6 \\
\hline 10.6 & 4.3 & 3.2 \\
\hline 10.7 & 13.3 & 34.4 \\
\hline 10.8 & 20.8 & 17.7 \\
\hline 10.9 & 15.3 & 5.4 \\
\hline
\end{tabular}

Note: NACE (Nomenclature des Activités Économiques dans la Communauté Européenne) is a European industry standard classification system similar in function to Standard Industry Classification (SIC) and North American Industry Classification System (NAICS) for classifying business activities. CZ-NACE 10.1- Preserved meat and meat products, CZ-NACE 10.2 - Preserved fish and fish products, CZ-NACE 10.3- Processed and preserved fruit and vegetables, CZ-NACE 10.4- Vegetable and animal oils and fats, CZ-NACE 10.5- Dairy products, CZ-NACE 10.6- Grain mill products, starches and starch products, CZ-NACE 10.7- Bakery and farinaceous products, CZ-NACE 10.8 -Other food products, CZ-NACE 10.9- Prepared animal feeds

Source: authors' processing based on "Panorama of Food Processing Industry" (2017)

Table 1: The share of the groups of NACE in the total sector turnover and total number of employees in 2016.

According to the numbers provided in Table 1, the highest shares in total turnover had the following NACE groups: Preserved meat and meat products, Dairy products, Other food products and Prepared animal feeds. For further analysis the following two groups of NACE were chosen: Preserved meat and meat products and Dairy products (Table 2).

In the last years the chosen sectors obtained a substantial financial investment support (from EU). The amount of investments to NACE 10.1 had been growing during the considered period, i.e. from 2011 to 2016 . The investments to NACE 10.5 were increasing until 2014, however, later it was declining. This fact has appeared interesting for us, which eventually motivated us to analyse the impact of investments on technical efficiency of food processing companies.

Food processing efficiency and total-factor productivity (TFP) growth in Czech food processing industry was investigated, for instance by Čechura and Hockmann (2017), Čechura and Malá (2014). These authors concluded that the most important and distinguish characteristic of Czech food processing is heterogeneity among firms as well as among sectors. Moreover, the differences in intra-sectoral heterogeneity suggest that the food processing industry will be the subject of accelerated structural change in the future. Another research that was conducted by Rudinskaya and Náglová (2018) was aimed at the analysis of the effects produced by subsidies of the EU Rural Development Programme (RDP) on meat processing firms. The results indicate a positive impact of subsidies on technical efficiency of meat processing firms, which, however, decreases over time.

Considering the lack of empirical studies focusing on the impact of subsidies on technical efficiency namely in the Czech Republic, the main objective of this paper is to assess the effect of investments on productivity and technical efficiency of Czech food processing companies, specifically, that focus on Preserved meat and meat products along with Dairy products.

\section{Materials and methods}

\section{Stochastic Frontier Analysis (SFA)}

Following Farrell (1957) many different methods have been considered for the estimation of efficiency. The two widely used approaches are the Data Envelopment Analysis (DEA), which is nonparametric and deterministic, and the Stochastic Frontier Analysis (SFA), which is, on the contrary, parametric and stochastic. The great advantage of SFA is the possibility

\begin{tabular}{|l|c|c|c|c|c|c|}
\hline Sector & 2011 & 2012 & 2013 & 2014 & 2015 & 2016 \\
\hline $\begin{array}{l}\text { Preserved meat } \\
\text { and meat products }\end{array}$ & 1997863 & 1508190 & 2462674 & 1654850 & 2405313 & 2412208 \\
\hline Dairy products & 1051070 & 1058409 & 1341208 & 1632203 & 1554808 & 1393530 \\
\hline
\end{tabular}

Note: CZ-NACE 10.1- Preserved meat and meat products, CZ-NACE 10.2 - Preserved fish and fish products, CZ-NACE 10.3- Processed and preserved fruit and vegetables, CZ-NACE 10.4- Vegetable and animal oils and fats, CZ-NACE 10.5- Dairy products, CZ-NACE 10.6- Grain mill products, starches and starch products, CZ-NACE 10.7- Bakery and farinaceous products, CZ-NACE 10.8 -Other food products, CZ-NACE 10.9- Prepared animal feeds

Source: authors' processing based on "Panorama of the food industry" (2017).

Table 2: Total investments in food processing industry in the Czech Republic in CZK. 
that it offers of decomposing productivity change into parts that have straightforward economic interpretation. The focus of SFA is to obtain an estimator for one of the components of TFP, the degree of technical efficiency (Pires and Garcia, 2012).

To study the determinants of technical efficiency we used the SFA methodology developed by Aigner et al. (1977). The SFA method is based on an econometric (i.e. parametric) specification of a production frontier. Using a generalized production function and panel data this method can be formalized by the following general mathematical notation:

$y_{i}=f\left(x_{i j t} ; \beta\right) \cdot \exp \left(\varepsilon_{i t}\right)$

where $y$ represents output, $x$ is a vector of inputs, $\beta$ is a vector of unknown parameters, and $\varepsilon$ is the error term. The subscripts $i$ and $j$ denote the firm and inputs, respectively, $t$ stands for time.

In this specific formulation, the error term is farm specific and is composed of two independent components, $\varepsilon_{i t}=v_{i t}-u_{i t}$. The first element, $v_{i t}$ is a random variable reflecting noise and other stochastic shocks entering into the definition of the frontier, such as shocks manifested in various unpredictable circumstances, such as employees' strikes, deteriorations of weather conditions, natural disasters etc. This term is assumed to be an independent and identically distributed normal random variable with zero mean and constant variance iid $\left[N \sim\left(0, \sigma_{v}^{2}\right)\right]$.

The second component, $u_{i t}$, captures technical inefficiency relative to the stochastic frontier. The inefficiency term $u_{i t}$ is nonnegative and it is assumed to follow a half-normal, truncated-normal, gamma or exponential distribution (Kumbhakar and Lovell, 2000).

An index for technical efficiency (TE) can be defined as the ratio of the observed output $(y)$ and maximum feasible output $\left(y^{*}\right)$ :

$T E_{i t}=\frac{y_{i t}}{y_{i t}^{*}}=\frac{f\left(x_{i j t} ; \beta\right) \cdot \exp \left(v_{i t}-u_{i t}\right)}{f\left(x_{i j t} ; \beta\right) \cdot \exp \left(v_{i t}\right)}=\exp \left(-u_{i t}\right)$

Because $y \leq y^{*}$, the TE index is bounded between 0 and 1 ; TE achieves its upper bound when a firm is producing the maximum output feasible level (i.e., $y=y^{*}$ ), given the input quantities. Jondrow et al. (1982) demonstrated that firm-level TE can be calculated from the error term $\varepsilon i$ as the expected value of $-u_{i}$ conditional on $\varepsilon_{i}$, which is given by
$E\left[u_{i} \mid \varepsilon_{i}\right]=\frac{\sigma_{*} \phi\left(\frac{\mu_{* i}}{\sigma_{*}}\right)}{\Phi\left(\frac{\mu_{* i}}{\sigma_{*}}\right)}+\mu_{* i}$

where $\phi(\cdot)$ represent the standard normal density and $\Phi(\cdot)$ the standard normal cumulative density functions; $\mu_{* i}=\frac{-\sigma_{u}^{2} \epsilon_{i}}{\sigma_{v}^{2}+\sigma_{u}^{2}}$ and $\sigma_{*}^{2}=\frac{\sigma_{v}^{2} \sigma_{u}^{2}}{\sigma_{v}^{2}+\sigma_{u}^{2}}$ for half normal distribution of inefficiency term;

$\mu_{* i}=\frac{\sigma_{v}^{2} \mu-\sigma_{u}^{2} \epsilon_{i}}{\sigma_{v}^{2}+\sigma_{u}^{2}}$ and $\sigma_{*}^{2}=\frac{\sigma_{v}^{2} \sigma_{u}^{2}}{\sigma_{v}^{2}+\sigma_{u}^{2}}$ for truncatednormal distribution of inefficiency term.

Thus, the TE measure for each farm is equal to

$T E_{i}=\exp \left(-E\left[u_{i} \mid \varepsilon_{i}\right]\right)$

\section{SFA and heterogeneity}

It is possible to take heterogeneity factors into account by including these effects (management level, access to investments etc.) in the mean and/or variance of the distribution of inefficiency (observed heterogeneity) or by randomizing of the parameters of the stochastic frontier model (unobserved heterogeneity).

\section{Unobserved heterogeneity}

During the past two decades various forms of econometric methods were developed that enable, especially using panel data, identify the unobserved heterogeneity. Unobserved heterogeneity can be taken into account by randomising some parameters of a model; in this case it is assumed that such a randomisation captures all time invariant unobserved heterogeneity. For example, the listed below models are models that able to introduce unobserved heterogeneity: True Fixed and Random Effects Model (Greene, 2005), Random Parameters Model (Greene, 2005) and Fixed-Management Model (Alvarez et al., 2006).

\section{Observed heterogeneity}

Observed heterogeneity can be introduced into a model specification by several methods. A common approach deals with incorporating a vector of variables zi that contains the information about heterogeneity directly into a model. In this case $z_{i}$ appears to be a goal function itself.

$y_{i}=\beta^{\prime} x_{i}+\alpha^{\prime} z_{i}+v_{i}-u_{i}$

Two other methods of examining the heterogeneity factors impact to technical inefficiency is the capturing heterogeneity factors by the variance parameter and the mean of the technical inefficiency term. 
The model for empirical study is based on Battese and Coelli (1995). It is supposed that the inefficiency terms $u$ it are non-negative random variables capturing firm-specific and time-specific deviations from the frontier, associated with technical inefficiency. In equation (5) $u_{-}$it is specified as:

$u_{i t}=z_{i t} \delta+w_{i t}$

where $z_{i t}$ is a vector of firm-specific time-variant variables (exogenous factors or variables explaining inefficiency) exogenous to the production process, and $\delta$ is an unknown vector of $J$ parameters to be estimated. The error term $w_{i t} \sim N\left(0, \sigma_{w}{ }^{2}\right)$ is truncated by the variable truncation point $-z_{i t} \delta$.

Battese and Coelli model (1995) allows for estimation of impact of different factors on technical inefficiency. Therefore, technical efficiency corresponding to the production frontier and inefficiency effects is defined as:

$T E_{i t}=\exp \left(-u_{i t}\right)=\exp \left\{-z_{i t} \delta-w_{i t}\right\}$

According to Färe (1975), for estimation a production function in the translogarithmic (transcendental logarithmic) form we used three production factors and a time variable. This translogarithmic production function can be written as follows:

$$
\begin{aligned}
& \ln \left(Y_{i t}\right)=\ln (A)+\alpha_{K} \ln \left(K_{i t}\right)+\alpha_{L} \ln \left(L_{i t}\right)+\alpha_{M} \ln \left(M_{i t}\right)+ \\
& \quad+\alpha_{T} T+0.5 \beta_{K K} \ln \left(K_{i t}\right) \ln \left(K_{i t}\right)+ \\
& \quad+0.5 \beta_{L L} \ln \left(L_{i t}\right) \ln \left(L_{i t}\right)+0.5 \beta_{M M} \ln \left(M_{i t}\right) \ln \left(M_{i t}\right)+ \\
& \quad+0.5 \alpha_{T T} T T+B_{K L} \ln \left(K_{i t}\right) \ln \left(L_{i t}\right)+ \\
& \quad+\beta_{K M} \ln \left(K_{i t}\right) \ln \left(M_{i t}\right)+\beta_{L M} \ln \left(L_{i t}\right) \ln \left(M_{i t}\right)+ \\
& \quad+\alpha_{K T} \ln \left(K_{i t}\right) T+\alpha_{L T} \ln \left(L_{i t}\right) T+\alpha_{M T} \ln \left(M_{i t}\right) T+v_{i t}-u_{i t}
\end{aligned}
$$

where $A$ is total factor productivity, $L$ is a labour variable, $K$ is a capital variable, $M$ is a material variable, $Y$ is an output variable, $T$ is a time trend variable representing technical change.

The difference in technical efficiency among firms can be explained by different factors. These factors are exogenous variables that are neither inputs to the production process nor outputs of the firm. Nonetheless, these factors can influence farm's performance. In this research it is assumed that exogenous variables impact technical efficiency and hence these factors are modelled in the inefficiency term. Empirical model for the research is based on Battese and Coelli (1995) model.

Specification developed by Battese and Coelli (1995) incorporates vector of explanatory variables $z_{i t}{ }^{\prime}$, which influences technical efficiency of a firm $i$ at time $t$ : $u_{i t}=z_{i t}^{\prime} \delta+w_{i t}$

where $\delta$ is a vector of unknown parameters, $w_{i t}$ is a random term defined by truncated-normal distribution, $z_{i t}{ }^{\prime}$ - is a transposed vector of data upon amortization.

The latter variable is used in the present analysis as a proxy of investments to a production process. It is done the following way: having collected data upon amortization per each firm, we considered an increase in this time series (between two neighbouring observations) as a presence of investment. On the contrary, if the difference between the two neighbouring observations is negative, it is considered as its absence. In the further analysis instead of $z_{i t}^{\prime}$ variable we used a dummy variable (1 stands for investment; 0 - no investment).

\section{TFP decomposition}

The ways of measuring the growth in total factor productivity (TFP) along with its decomposition have been a matter of concern for a number of researchers in various empirical studies on industrial productivity (Jorgenson, 1995, Kumbhakar and Knox Lovell, 2000). The main contribution of Pires and Garcia paper (2012) consisted in showing that a suitable decomposition of TFP can be applied to a fairly large sample for an extensive period of time in order to evaluate not just the role of technical progress and technical efficiency change, but also scale and allocative efficiency change as determinants of long-term growth. "The Divisia index has been widely used as a convenient measure of TFP growth over time and space" (Kumbhakar and Knox Lovell, 2000). Productivity change, when there are multiple inputs, is measured by, what is popularly known as, TFP change and is defined as:

$T \dot{F} P=\dot{y}-\sum_{j} s_{j}^{a} \dot{x}_{j}$,

where $\mathrm{s}_{j}^{a}=w_{j} x_{j} / C^{a}$ and $C^{a}=\sum_{j} w_{j} x_{j}$, with $w_{j}$ being the price of input $x_{j}$.

Having differentiated $\dot{y}$ (equation (1)) totally and using the definition of TFP change in equation (10), we obtain:

$$
\begin{aligned}
& T \dot{F} P=T C-\frac{\partial u}{\partial t}+\sum_{j}\left\{\frac{f_{j} x_{j}}{f}-s_{j}^{a}\right\} \dot{x}_{j} \\
& =(R T S-1) \sum_{j} \lambda_{j} \dot{x}_{j}+T C \\
& +T E C+\sum_{j}\left\{\lambda_{j}-s_{j}^{a}\right\} \dot{x}_{j} \\
& \text { where } T C=\frac{\partial \ln f(\cdot)}{\partial t}, T E C=-\frac{\partial u}{\partial t} \text {, } \\
& R T S=\sum_{j} \frac{\partial \ln y}{\partial \ln x_{j}}=\sum_{j} \frac{\partial \ln f(\cdot)}{\partial \ln x_{j}} \mid=\sum_{j} \frac{f_{j}(\cdot) x_{j}}{f(\cdot)} \equiv \sum_{j} \varepsilon_{j}
\end{aligned}
$$


is the measure of returns to scale and $\varepsilon_{j}$ are input elasticities defined at the production frontier, $f(x, t)$. At the same time $\lambda_{j}=\left\{f_{j} x_{j} / \sum_{k} f_{k} x_{k}\right\}=\varepsilon_{j} / R T S$ when $f_{j}$ is the marginal product of input $x_{j}$.

The ratio in (11), thus, decomposes TFP change into several components:

- scale component $(R T S-1) \sum_{j} \lambda_{j} \dot{x}_{j}$;

- technical change $(T C)=\frac{\partial \ln f(\cdot)}{\partial t}$

- technical efficiency change $(\mathrm{TEC})=-\frac{\partial u}{\partial t}$;

- allocative component $\sum_{j}\left\{\lambda_{j}-s_{j}^{a} \dot{x}_{j}\right.$, which capture either deviations of input prices from the value of their marginal rate of technical substitution from the ration of input prices $\left(f_{j} / f_{k} \neq w_{j} / w_{k}\right)$.

Having done the decomposition, we thus can study the impact of each of the components of TFP.

In the expressions that follow, $\varepsilon_{K}$ and $\varepsilon_{L}$ are output elasticities, RTS denotes returns to scale with $R T S=\varepsilon_{K}+\varepsilon_{L}, S_{K}$ and $s_{K}$ are the shares of capital and material in aggregate income, $g_{K}$ is the growth rate of capital $(\dot{K} / K)$ and $g_{L}$ is the growth rate of labor $(L / L) ; \lambda_{K}=\varepsilon_{K} / R T S$ and $\lambda_{L}=\varepsilon_{L} / R T S$ are defined as normalized shares of capital and labor in income. TFP change then can be estimated as follows (Kumbhakar and Knox Lovell (2000)):

$$
\begin{aligned}
g_{\text {TFP }} & =T P-\dot{u}+(R T S-1) \cdot\left[\lambda_{K} \cdot g_{K}+\lambda_{L} \cdot g_{L}\right] \\
& +\left[\left(\lambda_{K}-S_{K}\right) \cdot g_{K}+\left(\lambda_{L}-S_{L}\right) \cdot g_{L}\right]
\end{aligned}
$$

That is, total factor productivity growth can be split into four elements:

- technical progress, measured by $T P=\partial \ln f(t, K, L) / \partial t$

- $\quad$ change in technical efficiency, denoted by - $\dot{u}$;

- change in the scale of production, given by $(R T S-1) \cdot\left[\lambda_{K} \cdot g_{K}+\lambda_{L} \cdot g_{L}\right]$

- change in allocative efficiency, measured by $\left[\left(\lambda_{K}-s_{K}\right) \cdot g_{K}+\left(\lambda_{L}-s_{L}\right) \cdot g_{L}\right]$.

\section{Data set}

The panel data set was collected from the Albertina database. For the analysis we used the information from the final accounts of companies, the main activity of which is food processing. Study covers the period from 2011 till 2015. The whole database represents 9 branches of food processing industries. For the present analysis two of them (meat and milk) were chosen. After excluding the companies with numerous missing observations, the unbalanced panel data set contains 2854 observations received from 607 food processing Czech companies.

The following variables were used in the analysis: Output, Labour, Capital and Material. Output is represented by the total sales of goods, products and services of the food processing company. In order to avoid price changes, Output was deflated by the price index of food processing companies according to the branch $(2015=100)$. The Labour input is used in the form of total personnel costs per company, divided by the average annual wage. The data on annual wages were taken from the Czech Statistical Office. The Capital variable is represented by the value of tangible assets. Material variable is represented by total costs of material and energy consumption per company. Capital and Material variables were deflated by the price index of industrial sector $(2015=100)$. Output, Capital, Material variables are measured in thousand CZK. Since Labour variable is a coefficient (above-mentioned Labour variable definition), there is no necessity to deflate the variable to eliminate price changes.

According to the purpose of the study, an Investment variable was chosen for the analysis of investments value on technical efficiency. The variable is represented by the following way: having collected data upon amortization per each firm, we considered an increase in this time series (between two neighbouring observations) as a presence of investment (dummy "1"). On the contrary, if the difference between the two neighbouring observations is negative, it is considered as its absence (dummy “0”).

\section{Results and discussion}

\section{Technical efficiency estimation}

Table 3 and Table 4 provide an estimate of parameters of the production function for meat and milk processing firms correspondingly. The first-order estimated parameters are significant at $1 \%$ level of significance under z-test (see Table 3 ). The assumption of monotonicity and quasiconcavity is fulfilled for all production factors except for the Labour variable. Since the values of production factors were normalised by their arithmetic means after logarithmic transformation, in translogarithmic model these coefficients denote the variation or possible percentage change in aggregate output as a result of one per cent change in the input, that is, production elasticities.

All production elasticities are positive $\left(\beta_{K}, \beta_{L}, \beta_{M}>0\right)$; the highest elasticity displays production factor 


\begin{tabular}{|l|l|l|l|r|c|}
\hline & Parameters & Coef. & Std. Err. & $\mathbf{z}$ & P>z \\
\hline \multirow{5}{*}{ First-order parameters } & $\beta_{K}$ & 0.0591 & 0.0181 & 3.26 & 0.001 \\
\cline { 2 - 6 } & $\beta_{L}$ & 0.1761 & 0.0481 & 9.72 & 0.000 \\
\cline { 2 - 6 } & $\beta_{M}$ & 0.7699 & 0.0132 & 58.40 & 0.000 \\
\cline { 2 - 6 } & $\beta_{T}$ & -0.0532 & 0.0119 & -4.46 & 0.000 \\
\cline { 2 - 6 } & Constant & 0.0058 & 0.0152 & 0.38 & 0.704 \\
\hline \multirow{5}{*}{ Second-order parameters } & $\beta_{K K}$ & 0.0334 & 0.0190 & 1.76 & 0.079 \\
\cline { 2 - 6 } & $\beta_{L L}$ & 0.1730 & 0.0426 & 4.06 & 0.000 \\
\cline { 2 - 6 } & $\beta_{M M}$ & 0.1472 & 0.0122 & 12.10 & 0.000 \\
\cline { 2 - 6 } & $\beta_{T T}$ & 0.0863 & 0.0147 & 5.87 & 0.000 \\
\cline { 2 - 6 } & $\beta_{L K}$ & -0.0293 & 0.0219 & -1.34 & 0.180 \\
\cline { 2 - 6 } & $\beta_{K M}$ & 0.0094 & 0.0072 & 1.30 & 0.193 \\
\cline { 2 - 6 } & $\beta_{L M}$ & -0.1577 & 0.0218 & -7.22 & 0.000 \\
\cline { 2 - 6 } & $\beta_{K T}$ & 0.0025 & 0.0112 & 0.22 & 0.824 \\
\cline { 2 - 6 } & $\beta_{L T}$ & 0.0258 & 0.0127 & 2.03 & 0.042 \\
\cline { 2 - 6 } & $\beta_{M T}$ & -0.0331 & 0.0092 & -3.61 & 0.000 \\
\hline \multirow{3}{*}{ Parameters of variance (mean) in $u_{i t}$} & Investment & -91.6040 & 33.452 & -2.74 & 0.006 \\
\cline { 2 - 6 } & Constant & -92.8100 & 31.859 & -2.91 & 0.004 \\
\hline \multirow{3}{*}{ lambda } & & 70.1560 & 0.6790 & 103.31 & 0.000 \\
\hline
\end{tabular}

Source: authors' elaboration in STATA

Table 3: The estimation of production function parameters for meat processing firms (preserved meat and meat products).

\begin{tabular}{|c|c|c|c|c|c|}
\hline & Parameters & Coef. & Std. Err. & $\mathbf{z}$ & $\mathbf{P}>\mathbf{Z}$ \\
\hline \multirow{5}{*}{ First-order parameters } & $\beta_{K}$ & 0.0284 & 0.0098 & 2.88 & 0.004 \\
\hline & $\beta_{L}$ & 0.1879 & 0.0173 & 10.87 & 0.000 \\
\hline & $\beta_{M}$ & 0.7577 & 0.0129 & 58.56 & 0.000 \\
\hline & $\beta_{T}$ & 0.0049 & 0.0144 & 0.34 & 0.735 \\
\hline & Constant & 0.2122 & 0.0205 & 10.34 & 0.000 \\
\hline \multirow{10}{*}{ Second-order parameters } & $\beta_{K K}$ & 0.0273 & 0.0070 & 3.88 & 0.000 \\
\hline & $\beta_{L L}$ & 0.1763 & 0.0177 & 9.94 & 0.000 \\
\hline & $\beta_{M M}$ & 0.1752 & 0.0108 & 16.29 & 0.000 \\
\hline & $\beta_{T T}$ & -0.0003 & 0.0196 & -0.01 & 0.989 \\
\hline & $\beta_{L K}$ & -0.0373 & 0.0112 & -3.11 & 0.002 \\
\hline & $\beta_{K M}$ & -0.0151 & 0.0075 & -2.02 & 0.043 \\
\hline & $\beta_{L M}$ & -0.1229 & 0.0067 & -18.23 & 0.000 \\
\hline & $\beta_{K T}$ & 0.0078 & 0.0073 & 1.07 & 0.287 \\
\hline & $\beta_{L T}$ & -0.0240 & 0.0130 & -1.84 & 0.066 \\
\hline & $\beta_{M T}$ & 0.0127 & 0.0095 & 1.34 & 0.181 \\
\hline \multirow{2}{*}{ Parameters of variance (mean) in $u_{i t}$} & Investment & -65.262 & 19.7500 & -3.30 & 0.001 \\
\hline & Constant & -93.970 & 25.2500 & -3.72 & 0.000 \\
\hline \multicolumn{2}{|l|}{ lambda } & 26.19462 & 0.570143 & 45.94 & 0.000 \\
\hline
\end{tabular}

Source: authors' elaboration in STATA

Table 4: The estimation of production function parameters for milk processing firms (Dairy product).

Material (0.7699). The production factor Capital, in opposite, has low impact on firms' output (0.0591). Curvature assumption (quasi-concavity in inputs) is fulfilled in the case of all production factors, except Labour. The parameter $\lambda$ is the relation between the variance of $u_{i t}$ and $v_{i t}$. Thus, the parameter indicates the significance of technical inefficiency in the residual variation. A value larger than one suggests that variation in uit prevails the variation in the random component $v_{i t}$. Technical 
change has negative impact on production. It is characterised by Material-saving, and Capitaland Labour-intensive behaviour. The analysis determined slightly increasing, rather constant returns to scale in the case of meat processing industry. The results of parameters estimation, representing the sources of technical inefficiency (investments), show positive and significant, at $1 \%$ level of significance, impact of subsidies on investment on technical inefficiency.

The parameters of the model, given in Table 4, are statistically significant at $1 \%$ level of significance, except for Capital, that is significant at 5\% level. The slopes of the coefficients are positive, that is consistent with economic theory. The quasiconcavity assumption (diminishing marginal productivity) is fulfilled in the case of all production factors, except for Capital and Labour. The highest elasticity belongs to the Material production factor (0.7577). The other factors have lower impact on production output (0.1879 for Labour and 0.0284 for Capital). Estimated parameters of production factors satisfy the curvature assumption of quasi-concavity in inputs. The parameter $\lambda$ that is more than one indicates the presence of inefficiency. Technical change is characterised by positive impact on production, and Labour-saving, but Capital- and Materialintensive features. The sector demonstrates slightly decreasing returns to scale, that is the $1 \%$ change in inputs will lead to less than $1 \%$ change in output.

The results of estimation display positive and significant at $1 \%$ significance level impact of subsidies on investment on technical inefficiency.

\section{Efficiency, technology and productivity change}

Figure 1 and Figure 2 summarise the results for the change in efficiency, technical change and change in total factor productivity (TFP) for the investigated period (2011-2015).

Investments in fixed assets and technology could increase productivity by shifting out the firm's production frontier (altering the production technology) or by increasing technical efficiency (allowing producers to combine inputs so as to produce closer to the feasible frontier). Hence, the estimated parameters for the inefficiency part of the frontier model with respect to investment can be interpreted as efficiency effects by investment activities at a firm's level.

Having decomposed the TFP, it now appears that though TFP has been decreasing it was driven primarily by negative technical efficiency and technical change. Scale and allocative efficiency has only minor effect on TFP change.

Whereas milk processing firms have experienced a steady increase in technical change during this period, the change in efficiency appears to be stagnating. Hence, the change in total factor productivity on average increases by 0.5 per cent per year. The highest contribution to TFP was done by allocative efficiency and technical change. The effect of scale efficiency and technical efficiency was minor.

The results of the analysis are consistent with the results of a research done by Rudinskaya and Náglová (2018) dealt with the effect of subsidies

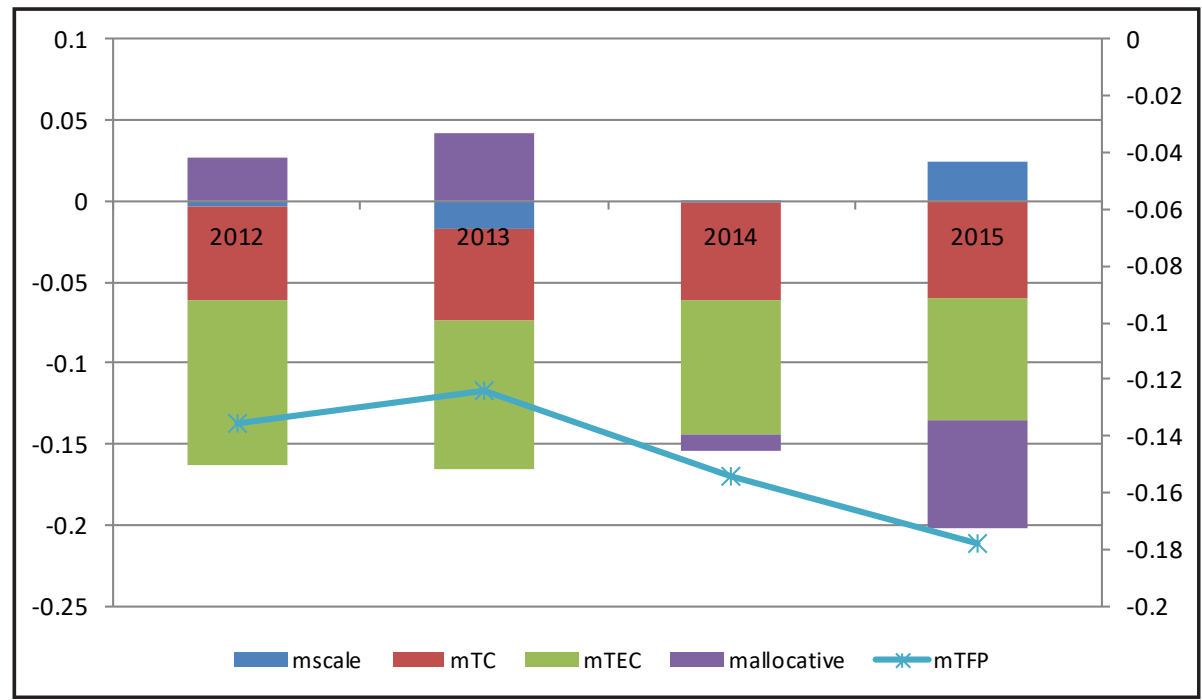

Source: authors' processing

Figure 1: Development of TFP and its components: Preserved meat and meat products. 


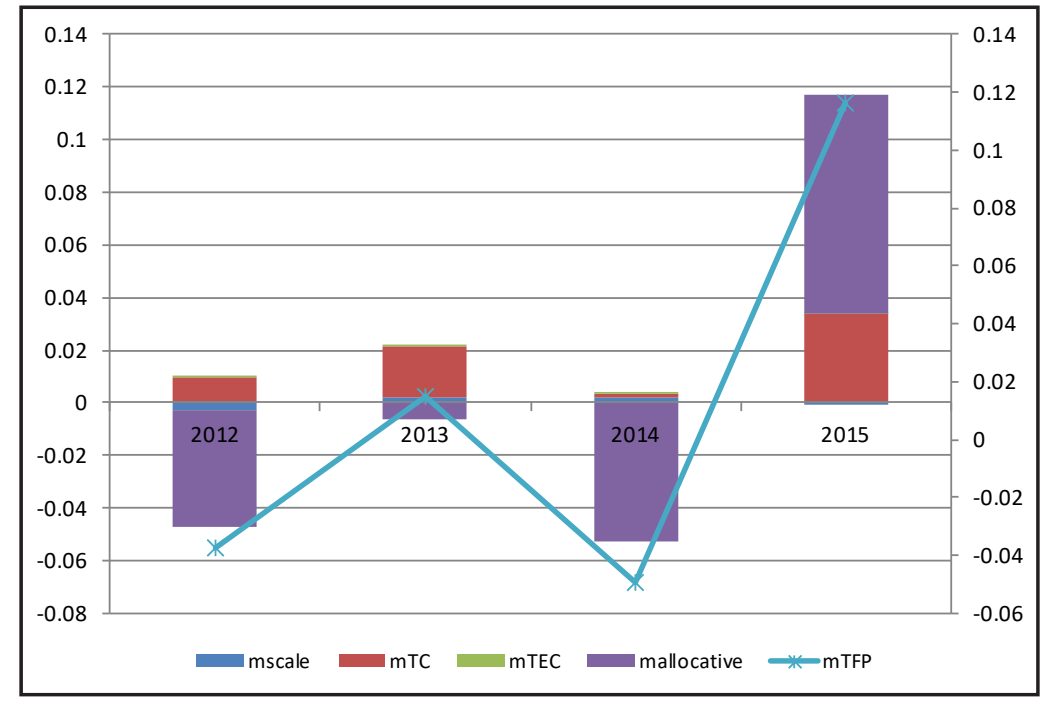

Source: authors' processing

Figure 2: Development of TFP and its components: Dairy products.

from EU Rural Development Programme (RDP). The results indicate positive impact of subsidies on meat processors' technical efficiency, which, though, decreases over time.

In general, we can say, that subsidies have a positive impact on technical efficiency. Nevertheless, the development of TFP in meat processing industry is decreasing with negative impact of technical efficiency. Apparently, meat processors did not use inputs effectively. The explanation of the reasons is discussible. Firms could increase their inputs through the higher cost due to investments, but their outputs remain the same. Submitted project and the implementation of investment did not reach adequate outputs. This was also found by Bergström (1998) and Rudinskaya and Naglova (2018). Subsidies can make firms less productive, because they give firms an inducement to change the mix of capital and labour and it can lead to inefficiencies. The subsidised firms might be over-invested in capital. According to Bergström (1998), subsidisation is positively correlated with growth of value added, and productivity of the subsidised firms seems to increase in the first year. However, after first year, the more subsidies a farm receives, the less productivity growths development was observed.

\section{Conclusion}

The present analysis makes use of a panel dataset to investigate empirically the impact of investments on productivity and efficiency of food processing firms in the Czech Republic. The two NACE groups with the highest share in total food processing sector revenue were chosen for the present analysis, namely, preserved meat and meat products and dairy products.

The empirical analysis was based on the estimation of production function using stochastic frontier approach. Thereafter using TFP decomposition based on Divisia index the change in efficiency, technical change and change in total factor productivity was calculated for the investigated period from 2011 till 2015. The empirical results made evident that investments in fixed assets increase technical efficiency of meat and milk processing companies.

In the case of meat processing companies TFP has been decreasing, driven primarily by negative technical efficiency and technical change. Scale and allocative efficiency has only minor effect on TFP change.

Milk processing firms have experienced an increase in technical change within the considered period, their technical efficiency was stagnating. Hence, the change in total factor productivity on average increased by 0.5 per cent per year. The allocative efficiency and technical change have contributed to TFP most of all. The effect of scale efficiency and technical efficiency was minor.

A number of studies of studies done by Špička and Machek (2015), Mezera and Špička (2013), Rudinskaya and Naglova (2018) evidenced that subsidies supporting investment and innovation activities have positive effect to overall competitiveness of subsidised companies in food processing sector. 
Investments, that induce the modernization of food industry production, positively contribute to the growth of technical efficiency. According to recent surveys (see Boudný and Janotová, 2015), higher labour productivity in Western EU countries is due to a higher level of organization, modernization and automation, which is associated with a relatively high investment intensity. In the Czech Republic, labour productivity is relatively low compared to other Member States. In this context, subsidies to modernization of food industry production are an important source of growth in technical efficiency. Moreover, it provides the opportunity to increase the processed capacity of raw milk. This implies that increased
TFP in food processing may trigger positive change in agricultural TFP.

This finding is an important message for policy makers with respect to the setting of CAP subsidies for the next programming period. However, more attention must be paid to effectiveness of investment facilities utilization.

\section{Acknowledgements}

The paper is a part of the solution of project QK1920398 supported by the Ministry of Agriculture of the Czech Republic - NAZV - program ZEMĚ.

\section{Corresponding authors}

Mgr. Elena Kuzmenko, Ph.D.

Department of Economics, Faculty of Economics and Management

Czech University of Life Sciences in Prague

Kamýcká 129, 16500 Prague - Suchdol, Czech Republic

E-mail:kuzmenko@pef.czu.cz

\section{References}

[1] Aigner, D., Lovell, C. K. and Schmidt, P. (1977) "Formulation and estimation of stochastic frontier production function models“, Journal of Econometrics, Vol. 6, No. 1, pp. 21-37. ISSN 0304-4076. DOI 10.1016/0304-4076(77)90052-5.

[2] Alvarez A., Arias C. and Greene W. (2003) "Fixed Management and time invariant technical efficiency in a random coefficient model“", Working Paper, Department of Economics, Stern School of Business, New York University

[3] Battese, G. E. and Coelli, T. J. (1995) "A model for technical inefficiency effects in a stochastic frontier production function for panel data“, Empirical Economics, Vol. 20, No. 2, pp. 325-332. E-ISSN 1435-8921, ISSN 0377-7332. DOI: 10.1007/BF01205442.

[4] Beck, M. and Dogot, T. (2006) "The Use of Impact Indicators for the Evaluation of Farm Investment Support - A Case Study Based on the Rural Development Programme for Wallonia 2000 - 2006“, Working Papers in Agricultural Economics, No. 3, pp. 69-77.

[5] Bergschmidt, A. Dirksmeyer, W., Efken J, Forstner, B. and Uetrecht, I. (2006) "Proceedings of the European Workshop on the Evaluation of Farm Investment Support, Investment Support for Improvement of Processing and Marketing of Agricultural Products", Braunschweig: FAL, 266 p, Working Paper Agric Econ 2006/03

[6] Bergschmidt, A. (2009) "Powerless Evaluation”, EuroChoices, No. 8, pp. 37-42. ISSN 1746-692X. DOI 10.1111/j.1746-692X.2009.00137.x.

[7] Bergström, F. (1998) "Capital subsidies and the performance of firm", SSE/EFI Working Paper Series in Economics and Finance, No. 258.

[8] Bernini, C. and Pellegrini, G. (2011) "How are growth and productivity in private firms affected by public subsidy? Evidence from a regional policy", Regional Science and Urban Economics, Vol. 41, No 3, pp. 253-265. ISSN: 0166-0462. DOI 10.1016/j.regsciurbeco.2011.01.005.

[9] Boudný, J. and Janotová, B. (2015) “Ekonomika výroby vepřového masa - postavení ČR v Evropě” (In Czech), Náš chov, Vol. 75, pp. 73-78. ISSN 0027-8068.

[10] Ciaian, P., Kancs, d'A., Michalek, J. (2015) "Investment Crowding-Out: Firm-Level Evidence from Germany (July 2015)", LICOS Discussion Paper 370/2015. DOI 10.2139/ssrn.2634922. 
[11] Coelli, T., Perelman, S. and Van Lierde, D. (2006) "CAP Reforms and Total Factor Productivity Growth in Belgian Agriculture: A Malmquist Index Approach", International Association of Agricultural Economists (IAAE), Annual Meeting, Queensland, Australia.

[12] Čechura L. and Hockmann H. (2017) "Heterogeneity in Production Structures and Efficiency: An Analysis of the Czech Food Processing Industry", Pacific Economic Review, Vol. 22, No. 4, pp. 702-719. ISSN 1468-0106. DOI 10.1111/1468-0106.12217.

[13] Čechura, L. and Malá, Z. (2014) "Technology and Efficiency Comparison of Czech and Slovak Processing Companies", Procedia Economics and Finance, Vol. 12, pp. 93-102, ISSN 2212-5671. DOI 10.1016/S2212-5671(14)00324-4.

[14] Färe, R. (1975) "Efficiency and the production function“, Journal of Economics, Vol. 35, No. 3, pp. 317-324. E-ISSN 1617-7134, ISSN 0931-8658. DOI 10.1007/BF01284619.

[15] Farrell, M. J. (1957) "The measurement of productive efficiency“, Journal of the Royal Statistical Society. Series A (General), Vol. 120, No. 3, pp. 253-290. DOI 10.2307/2343100.

[16] Ferto, I., Bakucz, Z., Bojnec, S. and Latruffe, L. (2012) "Investment and Financial Constraints in European Agriculture: Evidence from France, Hungary and Slovenia“, IEHAS Discussion Papers 1213. [Online]. Available: https://ideas.repec.org/p/ags/eaae11/114357.html [Accessed: 15 August, 2019].

[17] Forstner, B., Bergschmidt, A., Dirksmeyer, W., Ebers, H., Fitschen-Lischewski A., Margarian, A. and Heuer, J. (2009) "Ex-post evaluation of the German farm-investment support programme from 2000-2006“, Länderübergreifender Bericht 98, Thünen Institut, Braunschweig

[18] Greene, W. (2005) "Reconsidering heterogeneity in panel data estimators of the stochastic frontier mode“, Journal of Econometrics, Vol. 126, No. 2, pp. 269-303. ISSN 0304-4076. DOI 10.1016/j.jeconom.2004.05.003.

[19] Hurňáková, J., Bartová, L. and Fandel, P. (2016) "Efficiency and productivity of the Slovak agricultural investment support beneficiaries", International Scientific Days 2016, The Agri-Food Value Chain: Challenges for Natural Resources Management and Society, June, 2016, pp. 923-930. ISBN 978-80-552-1503-7. DOI 10.15414/isd2016.s12.03.

[20] Jondrow, J., Lovell, C. K., Materov, I. S. and Schmidt, P. (1982) "On the estimation of technical inefficiency in the stochastic frontier production function model", Journal of Econometrics, Vol. 19, No, 2-3, pp. 233-238. ISSN 0304-4076. DOI 10.1016/0304-4076(82)90004-5.

[21] Jorgenson, D. (1995) "Productivity: Postwar U.S. Economic Growth". Cambridge: MIT Press. ISBN 9780262512893.

[22] Kumbhakar, S. C. and Knox Lovell, C.A. (2000) "Stochastic Frontier Analysis", Cambridge University Press, Cambridge. ISBN 978-0521666633. DOI 10.1017/CBO9781139174411.

[23] Mezera, J. and Špička, J. (2013) "Economic Effects of Investment Support of Adding Value to Food", Agris on-line Papers in Economics and Informatics, Vol. 5, No.1, pp. 39-49. ISSN 1804-1930. DOI 10.22004/ag.econ.148102.

[24] Ministry of Industry and Trade Czech Republic (2017) "Panorama of the food industry". [Online]. Available: https:/www.mpo.cz/assets/en/industry/manufacturing-industry/panorama-of-themanufacturing-industry/2018/9/Panorama-2017-en.pdf [Accessed: $10 \mathrm{Julz,}$ 2019].

[25] Pires, J. O. and Garcia, F. (2012) "Productivity of nations: a stochastic frontier approach to TFP decomposition", Economics Research International, Vol. 2012, 19 p. DOI 10.1155/2012/584869.

[26] Ratinger, T., Medonos, T. and Hruska, M. (2014) "The Assessment of the effects of the investment support scheme in the Czech Republic", Poster paper prepared for presentation at the EAAE 2014 Congress Agri-Food and Rural Innovations for Healthier Societies. 
[27] Rudinskaya, T. and Náglová, Z. (2018) "Impact of Subsidies on Technical Efficiency of Meat Processing Companies", AGRIS on-line Papers in Economics and Informatics, Vol. 10, No. 1, pp. 61-70. ISSN 1804-1930. DOI 10.7160/aol.2018.100106.

[28] Špička, J. and Machek, O. (2015) "Change in the production efficiency of European specialized milk farming”, Agricultural Economics, Vol. 61, No 1, pp. 1-13. E-ISSN 1805-9295, ISSN 0139-570X. DOI 10.17221/112/2014-AGRICECON. 